Goldschmidt 2021 Abstract

https://doi.org/10.7185/gold2021.7003

\section{Experimental suite for evaluating metastable nucleation precursors and their transformation}

\author{
ANDREW LAUER ${ }^{1}$, ALEJANDRO FERNANDEZ- \\ MARTINEZ ${ }^{2}$, ROLAND HELLMANN ${ }^{3}$ AND ALEXANDER \\ E.S. VAN DRIESSCHE ${ }^{2}$ \\ ${ }^{1} \mathrm{CNRS}$, ISTerre \\ ${ }^{2}$ ISTerre, Univ. Grenoble-Alpes, CNRS \\ ${ }^{3}$ ISTerre
}

Presenting Author: andrew.lauer@univ-grenoble-alpes.fr

Experimental studies over the past decades have highlighted the importance of complex, particularly multiple-step, nucleation pathways during mineral formation in both inorganic and biomineralization environments ${ }^{1}$. Many of these pathways can be catalogued as a distinct two-step process where one phase forms and then transforms into a second phase, something that has been proposed as a means for the concentration, transportation, and/or temporary storage of ions in biomineralization ${ }^{2,3}$ but is also used to describe the behavior of (in)organic solutions with high supersaturation $^{4}$.

Using strontium sulfate (celestine) and its metastable hydrated precourser phase, we demonstrate how a suite of microscopic and spectroscopic tools can be successfully deployed to study the phases that form during multi-step nucleation pathways and the physico-chemical dependance of the reaction kinetics. In situ experiments track the concentrations of ions (Raman) and solid phases (XRD) during the transformation reaction. SEM, TEM and optical microscopy have shown the macrostructural differences between the phases with optical microscopy allowing for in situ tracking of the phases with spatial and temporal resolution.

Below is the temporal evolution of precipitants in a diffusionmediated $\mathrm{Sr}_{-} \mathrm{SO}_{4}-\mathrm{H}_{2} \mathrm{O}$ system over a period of five hours. Initially, hemihydrate needles form at the interface between $\mathrm{SrCl}_{2}$ and $\mathrm{Na}_{2} \mathrm{SO}_{4}$ solutions. Over time, the needles dissolve and reprecipitate on the surface of the reactor as celestine. This dissolution occurs preferentially in $\mathrm{Sr}^{2+} / \mathrm{Cl}^{-}$rich environments. The capillary diameter is $1.8 \mathrm{~mm}$.

Critically, it has been shown that solution mediated dissolution is the sole transformation mechansim and that the reaction kinetics are controlled by the the local physico-chemical environment, particularly ionic strength.

[1] De Yoreo, J. J. et al. Science. 2015, 349 (6247).

[2] Beniash, E. et al. Proc. R. Soc. B Biol. Sci. 1997, 264 (1380).

[3] Addadi, L. et. al Advanced Materials. 2003, 959-970.

[4] Sun, W. et al. CrystEngComm 2017, 19 (31).

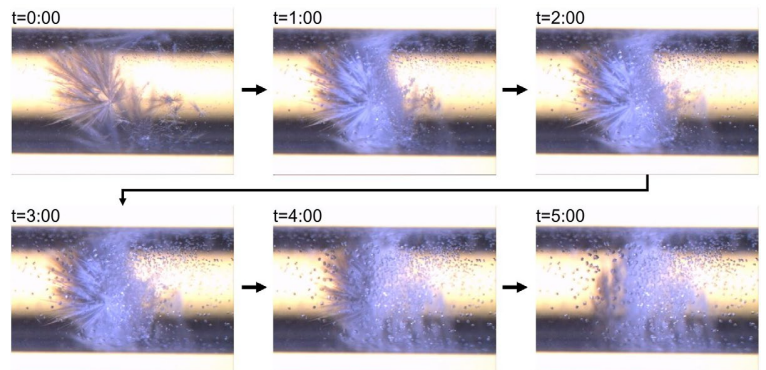

